\title{
Analysis of genetic relationships and identification of lily cultivars based on inter-simple sequence repeat markers
}

\author{
G.F. Cui*, L.F. Wu*, X.N. Wang, W.J. Jia, Q. Duan, L.L. Ma, \\ Y.L. Jiang and J.H. Wang
}

National Engineering Research Center for Ornamental Horticulture, Yunnan Key Laboratory for Flower Breeding, Flower Institute of Yunnan Agricultural Science Academy, Kunming, China

*These authors contributed equally to this study. Corresponding author: J.H. Wang E-mail: otlily@163.com

Genet. Mol. Res. 13 (3): 5778-5786 (2014)

Received June 10, 2013

Accepted October 30, 2013

Published July 29, 2014

DOI http://dx.doi.org/10.4238/2014.July.29.5

ABSTRACT. Inter-simple sequence repeat (ISSR) markers were used
to discriminate 62 lily cultivars of 5 hybrid series. Eight ISSR primers
generated 104 bands in total, which all showed $100 \%$ polymorphism,
and an average of 13 bands were amplified by each primer. Two software
packages, POPGENE 1.32 and NTSYSpc 2.1 , were used to analyze
the data matrix. Our results showed that the observed number of alleles
$\left(N_{\mathrm{A}}\right)$, effective number of alleles $\left(N_{\mathrm{E}}\right)$, Nei's genetic diversity $(H)$, and
Shannon's information index $(I)$ were $1.9630,1.4179,0.2606$, and
0.4080 , respectively. The highest genetic similarity $(0.9601)$ was observed
between the Oriental x Trumpet and Oriental lilies, which indicated that
the two hybrids had a close genetic relationship. An unweighted pair-
group method with arithmetic means dendrogram showed that the 62 lily
cultivars clustered into two discrete groups. The first group included the
Oriental and OT cultivars, while the Asiatic, LA, and Longiflorum lilies 
were placed in the second cluster. The distribution of individuals in the principal component analysis was consistent with the clustering of the dendrogram. Fingerprints of all lily cultivars built from 8 primers could be separated completely. This study confirmed the effect and efficiency of ISSR identification in lily cultivars.

Key words: Lily; Inter-simple sequence repeat; Cultivar identification; Genetic relationship

\section{INTRODUCTION}

Lily is a very important flower in international flower market. Since the introduction of China's wild lily into Europe during the 18th century, lilies became common ornamental plants whose varieties are largely bred for cut flowers. The breeding history of lilies can be traced back more than 200 years (Peng, 2002). As of 2008, more than 9465 lily varieties have been registered (Lim et al., 2008), which are classified into nine types by the UK Royal Horticultural Society based on the species that were used as parents for hybridization (Sato and Miyoshi 2007). Lily varieties update rapidly. With the breeding and popularization of a large number of new varieties, it is increasingly important to safeguard the interests of producers and breeders by identifying cultivars to ensure their authenticity and purity. In addition, retaining the genetic diversity between varieties is the fundamental guarantee for sustainable breeding and pest resistance. Traditionally, morphological traits are often used to identify cultivars and evaluate genetic diversity, but they have some disadvantages including long life cycle, less useful marks, and low reliability. Molecular marker technology provides a new way to identify cultivars and evaluate genetic diversity. DNA-based markers allow direct comparisons of different cultivars at the molecular level. Compared with other molecular markers such as randomly amplified polymorphic DNA (RAPD), inter-simple sequence repeat (ISSR) markers (Zietkiewicz et al., 1994) have showed more polymorphism and reproducibility (Qian et al., 2001). In addition, the ISSR technique is easy and economical, and it has been used successfully in genetic diversity studies of many plants, including Jatropha curcas (Grativol et al., 2011), spring orchid (Wang et al., 2009a), Auricularia auricula (Tang et al., 2010), clematis (Gardner and Hokanson, 2005), and loquats (Wang et al., 2010). ISSR markers can also be used to identify cultivars of Curcuma (Taheri et al., 2012) and strawberry (Arnau et al., 2002); detect the authenticity of hybrid offspring in Coffea (Ruas et al., 2003), mungbean (Khajudparn et al., 2012), and Phyllostachys (Lin et al., 2010) including lily (Wang et al., 2009b; Wu et al., 2009); and test asexual reproduction strain stability in lily (Liu and Yang, 2012; Xi et al., 2012). To date, there have been very few reports using ISSRs to differentiate varieties of lily hybrids.

In this paper, ISSR molecular markers were used to analyze the genetic diversity and build DNA fingerprints of lily cultivars to provide molecular evidence to protect and identify varieties.

\section{MATERIAL AND METHODS}

\section{Plant materials}

The plant samples included 62 lily varieties, which were planted in a greenhouse. The 
details of the hybrid categories that were used in the study are listed in Table 1. All samples were stored in the Flowers Institute, Yunnan Academy of Agricultural Sciences, Yunnan, China.

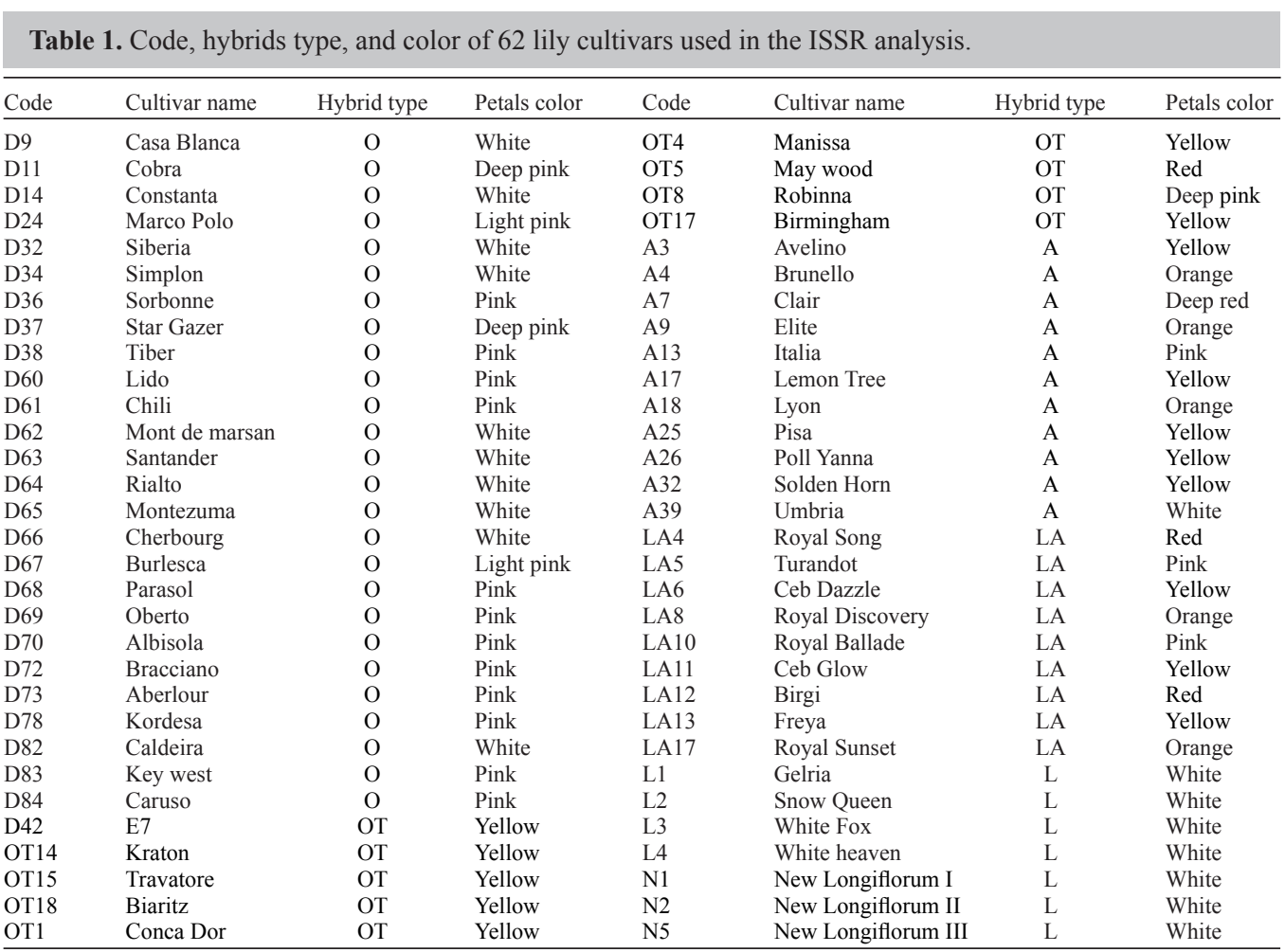

White O, OT, A, LA and L respectively represent Oriental lily hybrids, Oriental-Trumpet lily hybrids, Asiatic lily hybrids, Longiflorum-Asiatic lily hybrids, and Longiflorum lily hybrids.

\section{DNA extraction}

For each type of lily, two fresh leaves were collected from 10 different plants. Total genomic DNA was extracted from the pooled samples from the 10 individuals using the cetyltrimethylammonium bromide method of Jin et al. (2003) and Tian et al. (2010), with minor modifications. The DNA concentration was estimated using the absorbance at $260 \mathrm{~nm}$ (A260). The purity of the DNA extracts was measured using the ratio of the absorbance at 260 and 280 $\mathrm{nm}$ (A260/A280). Only DNA with an A260/A280 ratio of 1.8 to 2.1 was used (at a dilution of $10 \mathrm{ng} / \mu \mathrm{L}$ ) as a template for polymerase chain reaction (PCR) amplification.

\section{Primer screening and PCR amplification}

A total of 36 ISSR primers were synthesized by the Shanghai Sangon Biological Company. After the initial screening, 8 of the 36 primers produced clear banding patterns and were used for further analysis (Table 2). 
Table 2. Eight primers were selected for ISSR fingerprinting of 62 lily cultivars.

\begin{tabular}{lccc}
\hline Primer code & Sequence & Size in bp & Annealing temperature $\left({ }^{\circ} \mathrm{C}\right)$ \\
\hline R-808 & $(\mathrm{AG})_{8} \mathrm{C}$ & 17 & 52 \\
$\mathrm{R}-815$ & $(\mathrm{CC})_{8} \mathrm{G}$ & 17 & 52 \\
$\mathrm{R}-818$ & $(\mathrm{CA})_{8} \mathrm{G}$ & 17 & 52 \\
$\mathrm{R}-801$ & $(\mathrm{TC})_{7} \mathrm{GGA}$ & 17 & 52 \\
$\mathrm{R}-868$ & $(\mathrm{GAA})_{6}$ & 18 & 48 \\
$\mathrm{R}-857$ & $(\mathrm{AC})_{8} \mathrm{AG}$ & 18 & 54 \\
R-809 & $(\mathrm{CT})_{8} \mathrm{RA}$ & 20 & 53 \\
R-895 & $(\mathrm{AG})_{2} \mathrm{TTGGTAG}(\mathrm{CT})_{2}$ TGATC & 20 & 58 \\
\hline
\end{tabular}

Different concentrations of template DNA and Taq DNA polymerase were tested for the optimal amplification of products. The optimized amplification reaction mixture $(25 \mu \mathrm{L})$ contained $20 \mathrm{ng}$ DNA template with the PCR buffer $[50 \mathrm{mM} \mathrm{KCl} ; 10 \mathrm{mM}$ Tris- $\mathrm{HCl}, \mathrm{pH} 8.3$; $1.5 \mathrm{mM} \mathrm{MgCl2}$; and $0.001 \%(\mathrm{w} / \mathrm{v})$ gelatin], $0.5 \mu \mathrm{M}$ each primer, $200 \mu \mathrm{M} \mathrm{dNTPs}, 1.0 \mathrm{U}$ Taq DNA polymerase, and PCR-grade $\mathrm{dH}_{2} \mathrm{O}$.

Amplification was performed using a thermocycler (Eppendorf Mastercycler Gradient, Germany). The thermal cycling parameters were an initial denaturation at $94^{\circ} \mathrm{C}$ for $5 \mathrm{~min} ; 42$ cycles of a denaturation step at $94^{\circ} \mathrm{C}$ for $40 \mathrm{~s}$, an annealing step at $52^{\circ} \mathrm{C}$ for $45 \mathrm{~s}$ (with variable temperatures for different primers), and an extension step at $72^{\circ} \mathrm{C}$ for $90 \mathrm{~s}$; and a final elongation step at $72^{\circ} \mathrm{C}$ for $8 \mathrm{~min}$.

\section{Electrophoresis and ISSR data analysis}

The PCR products were electrophoresed on $2 \%$ horizontal agarose gels (Promega) in 1X Tris, borate, ethylenediaminetetraacetic acid buffer at $5 \mathrm{~V} / \mathrm{cm}$. The agarose gels were stained with $2.5 \mu \mathrm{g} / \mathrm{mL}$ ethidium bromide and photographed on an ultraviolet transilluminator. The experiment was performed twice, and only the reproducible bands were recorded. ISSR fragments were treated as a unit characteristic that were scored as present (1) or absent ( 0$)$ for each of the markers. The POPGENE (version 1.32) (Yeh and Boyle, 1997; Zhao et al., 2010) and NTSYS-pc (version 2.10) (Lewontin, 1972) software were used to analyze the binary data. The percentage of polymorphic loci (PPB), observed number of alleles $\left(N_{\mathrm{A}}\right)$, effective number of alleles $\left(N_{\mathrm{E}}\right)$, Shannon's information index $(I)$ (Lewontin, 1972), and Nei's genetic diversity $(H)$ (Nei, 1973) were calculated using POPGENE 1.32. The genetic distances obtained were used to create a dendrogram using unweighted pair-group method with arithmetic means (UPGMA) cluster analysis (Senthil Kumar et al., 2009; Zhao et al., 2010). NTSYS-pc 2.10 was used to perform principal component analysis (PCA) (Senthil Kumar et al., 2009; Tian et al., 2010).

\section{RESULTS}

\section{Products of ISSR amplification}

A total of 104 clear and reproducible bands were amplified using the eight selected primers, which all showed $100 \%$ polymorphism. The eight primers each produced a different number of bands, which ranged from 10 (primer-808) to 18 (primer-857), with an average of 13 bands that were amplified by each primer. The size of the bands varied between 150 and 1200 
bp. All samples could be distinguished based on the differences in their ISSR banding patterns.

\section{Genetic relationships}

The genetic diversity parameters of all samples and the five types of lilies are summarized in Table 3. $N_{\mathrm{E}}$ and $H$ are two of the most commonly used indicators of genetic variation (Miao et al., 2008; Zeng et al., 2010). For all 62 lily samples, $N_{\mathrm{A}}, N_{\mathrm{E}}, H$, and $I$ values were $1.9630,1.4179,0.2606$, and 0.4080 , respectively. Among the five types of lilies, the LA lilies exhibited the highest genetic diversity $(H=0.2127 ; I=0.3219)$. The lowest genetic diversity was observed among the Asiatic lilies $(H=0.1683 ; I=0.2656)$. The two genetic diversity parameters $(H$ and $I)$ followed a similar trend among the five types of lilies, namely, LA hybrids $>$ Oriental hybrids $>$ Longiflorum hybrids $>$ OT hybrids $>$ Asiatic hybrids.

Table 3. Genetic parameters for five hybrid types of lily from ISSR analysis.

\begin{tabular}{lcccrr}
\hline Lily type & Sample size & $N_{\mathrm{A}}$ & $N_{\mathrm{E}}$ & $H$ & \multicolumn{1}{c}{${ }$} \\
\hline Oriental & 28 & 1.7315 & 1.3252 & 0.1969 & 0.3050 \\
Oriental x Trumpet & 8 & 1.5648 & 1.2844 & 0.1725 & 0.2657 \\
Asiatic & 11 & 1.6204 & 1.2653 & 0.1683 & 0.2656 \\
Longiflorum x Asiatic & 9 & 1.3593 & 1.3593 & 0.2127 & 0.3219 \\
Longiflorum & 7 & 1.4907 & 1.3313 & 0.1891 & 0.2784 \\
Total & 63 & 1.9630 & 1.4179 & 0.2606 & 0.4080 \\
\hline
\end{tabular}

$N_{\mathrm{A}}=$ observed number of alleles; $N_{\mathrm{E}}=$ effective number of alleles; $H=$ Nei's gene diversity; $I=$ Shannon's Information index.

The similarity coefficients were used to construct the genetic similarity matrix of 62 lily genetic materials based on the bands that were amplified by PCR with the eight ISSR primers. The similarity coefficients between pairs of the various types of lilies ranged from 0.8419 to 0.9561 (Table 4 ). The highest genetic similarity (0.9561) was observed between the OT and Oriental lilies, which was followed by that between the LA lilies and the Asiatic and Longiflorum lilies. These results indicated that the derived hybrids and their parents were genetically more closely related at the molecular level. The morphology of LA hybrids is more like Asian lilies; their similarity coefficient (0.9345) was higher than that of LA hybrids with Longiflorum lilies (0.8797). The pairwise analysis of the genetic distance between individuals revealed the considerable genetic diversity of the different lily hybrid series.

Table 4. Similarity coefficients of five lily hybrid series.

\begin{tabular}{lcccc}
\hline pop ID* & O & OT & A & LA \\
\hline OT & 0.9561 & & & \\
A & 0.8752 & 0.8793 & 0.9345 & \\
LA & 0.8459 & 0.8540 & 0.8630 & 0.8797 \\
L & 0.8419 & 0.8459 &
\end{tabular}

Each letter represents a lily hybrids that same with Table 1.

\section{Cluster analysis}

The dendrogram (Figure 1) that was generated by the UPGMA cluster analysis of the Jaccard's similarity coefficients showed that the 62 lily cultivars clustered into two discrete 
groups. The first group included all Oriental and OT lilies. Asiatic, LA, and Longiflorum lilies were combined in the second cluster. The clustering results were consistent with the classification of the different varieties within each lily hybrid series. Two cultivars of the same hybrid series with a close genetic relationship may not necessarily have the same flower color. For example, the first cluster included 27 Oriental lily varieties, and the cultivar "Siberia" (D32) was closer to "Cobra" (D11) than to the white flower cultivar "Casablanca" (D9). Five OT lilies (OT14, OT1, OT4, OT15, and OT18) clustered at Jaccard's similarity coefficient 0.81 in advance, and then they were grouped together with four other OT lilies and Oriental hybrids. Oriental lilies were one parent of the OT hybrids, which caused a close genetic relationship between these two lily varieties. The second cluster included the Asian, LA, and Longiflorum lilies, and the Longiflorum hybrids clustered into a separate group. The LA lily is a relatively new hybrid series that was bred from Asian and Longiflorum hybrids, which have a flower shape and color that is more similar to Asian hybrids than Longiflorum hybrids.

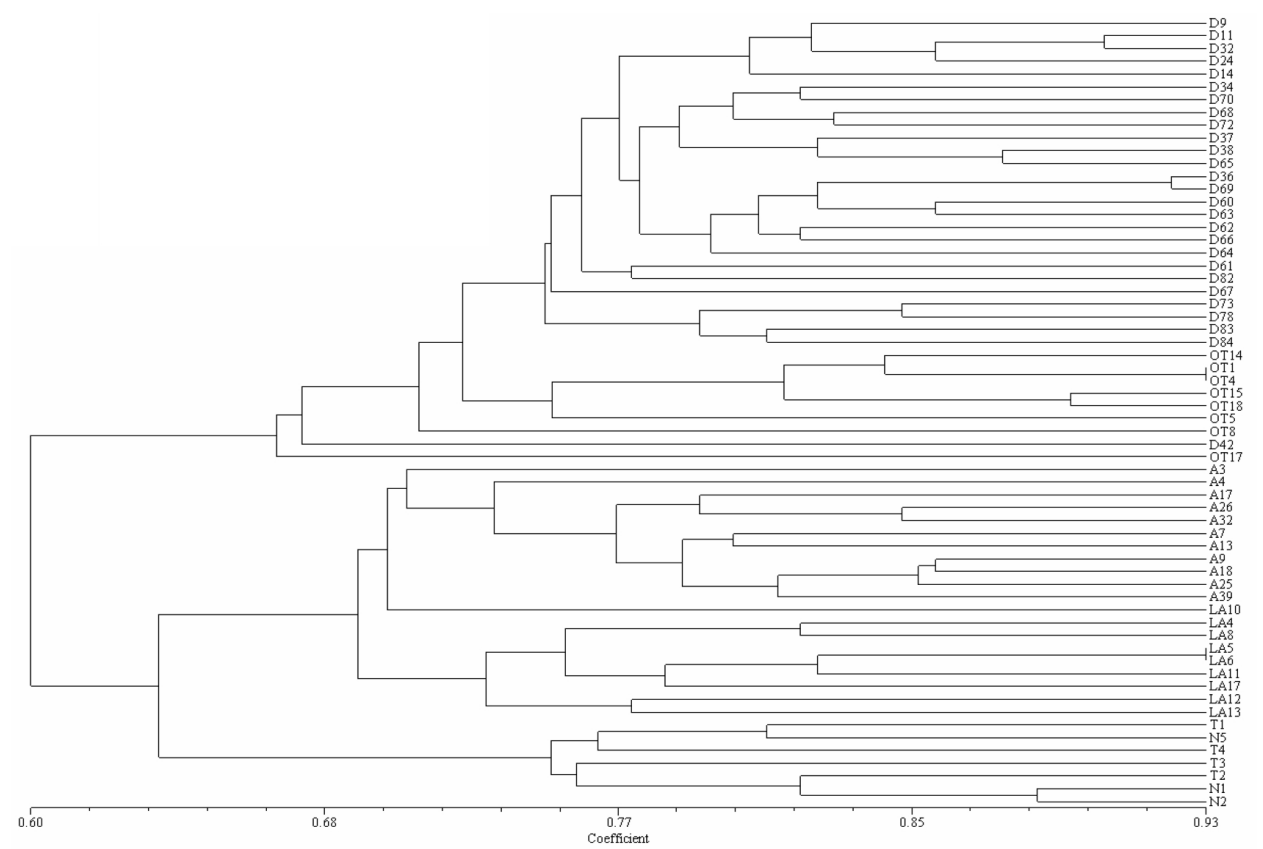

Figure 1. Unweighted pair-group method with arithmetic means dendrogram estimating the genetic relationships among 62 lily cultivars based on Jaccard's coefficient. Cultivar names are listed in Table 1.

\section{PCA analysis}

The genetic relationships among the 62 lily samples were further analyzed by PCA (Figure 2). The first three principal components explained 19.86, 7.79, and 5.69\% of the total variation. The overall distribution of individuals in the PCA pattern was consistent with the clustering pattern of the UPGMA dendrogram. The Oriental, Asiatic, and Longiflorum lilies could be distinguished by the first principal component, whereas the OT and LA lilies can be separated by the second and third principal components. 


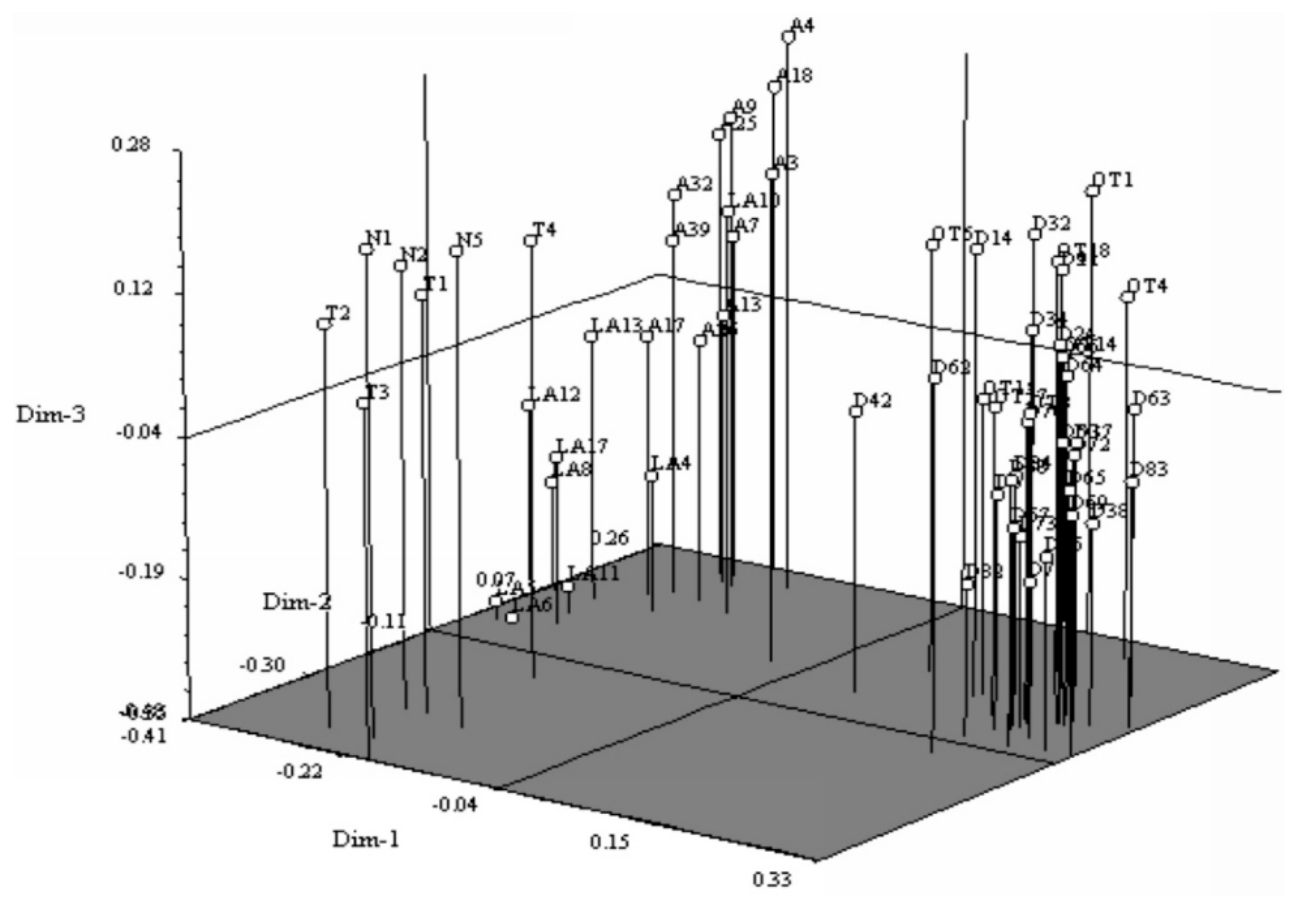

Figure 2. Principal component analysis of 62 lily cultivars. Cultivar names are listed in Table 1.

\section{DISCUSSION}

This study confirmed the effect and efficiency of lily cultivar identification by ISSR. ISSR markers can reveal more genomic polymorphisms than techniques such as restriction fragment length polymorphisms, simple sequence repeats, and RAPDs. Rao et al. (2007) used ISSR to analyze chickpea cultivars and indicated that six polymorphic ISSR primers could be used to evaluate the genetic diversity of all varieties, while nearly 30 primers were required for RAPD. A similar result was also obtained from the lily genetic relationship analysis with RAPD and ISSR. In RAPD fingerprinting, 22 primers generated 224 bands in total, and only 163 bands showed polymorphism (Zuo et al., 2005). In this study, the 8 primers amplified 104 polymorphic loci, and the polymorphism rate was $100 \%$. Furthermore, ISSR markers have another advantage in lily: there are no strict requirements for the quality of extracted DNA, which is particularly important for lilies because of their high polysaccharide content in all nutritive organs as compared with other plants. Therefore, ISSR genotyping is a suitable method for studying the genetic diversity of lilies and for the first time were used for the molecular identification of lily cultivars.

The result of the ISSR analysis of 62 lily cultivars showed that the genetic similarity coefficients had minor changes (0.8419-0.9561) between different hybrid series, and the Nei genetic diversity index had significant differences (0.1683-0.2127). The differences in genetic parameters indicated that lily cultivars had rich genetic diversity. Digital fingerprinting of all lily cultivars built from 8 primers could be separated completely. This observed number of al- 
leles may have been influenced by the sampling strategy, as lily cultivars belonged to different hybrid series. For Oriental lilies, the number of alleles observed $\left(N_{\mathrm{A}}=1.7315\right)$ is larger than the effective number of alleles $\left(N_{\mathrm{E}}=1.3252\right)$, which might be because of the large number of Oriental lily samples. From the perspective of morphological differences, if different cultivars within the same hybrid series have similar phenotypes, their $N_{\mathrm{A}}$ and $N_{\mathrm{E}}$ will be closer.

Lily cultivars have more ploidy types, and their genomes are highly heterozygous ( $\mathrm{Li}$ et al., 2011). Distinct differences exist between hybrid series because of the species, the number of original parents, and the number of generations of hybridization. At present, various hybridization techniques produced the richness in the types of lily hybrids. The complex lily hybrid series were bred by integrating the advantages of different pre-existing hybrid series. The LA (Longiflorum x Asiatic) and OT (Oriental x Trumpet) lily hybrids are considered major breakthroughs in the lily breeding industry (Zhou et al., 2008). For the composite hybrid series, the cultivars usually cluster with the parental series in the dendrogram. For example, the LA lily "Royal Ballade" first clustered with the Asian lilies group instead of other varieties of LA hybrids, which indicated a close genetic relationship between the two lilies. This study revealed that two varieties with similar petal shapes among Oriental lilies grouped together. Longiflorum hybrids have only two original parents and are easy to cross. The seedlings from germination to flowering only need 1.5 years, and the period of bulb incubation is much shorter than that of Asian lilies, Oriental lilies, and other hybrids. Therefore, the Longiflorum lilies experienced higher hybrid genomic recombination and obtained abundant genetic diversity $(H=0.1891 ; I=0.2784)$. Five OT lilies of the same color comprised a cluster, and then they joined with the four OT cultivars that had a different flower color than that of the former five varieties. OT5 and OT8 are the red flower varieties, while D42 was a potted variety with short plants, which was a trait that made it different from the other eight cut flower varieties. The main color of OT17 is yellow, but a red halo and red glands were distributed in the petals, which may be because of its red parent.

In this study, ISSR markers were used to evaluate the genetic relationships of different lily hybrid series. The cluster and PCA based on ISSR polymorphism indicates that ISSR markers can be used to quickly and accurately identify lily hybrids and determine the exact type of an unknown lily variety, even though lily cultivars have a complex genetic background.

\section{ACKNOWLEDGMENTS}

Research supported by the National High Technology Research and Development Program of China (Grant \#2011AA100208) from the Ministry of Science and Technology of the People's Republic of China and Science and Technology Projects (Grant \#2012BB011) in Yunnan Province, China.

\section{REFERENCES}

Arnau G, Lallemand J and Bourgoin M (2002). Fast and reliable strawberry cultivar identification using inter simple sequence repeat (ISSR) amplification. Euphytica 129: 69-79.

Gardner N and Hokanson SC (2005). Intersimple sequence repeat fingerprinting and genetic variation of Clematis cultivars and commercial germplasm. Hort. Sci. 40: 1982-1987.

Grativol C, da FL-M, Hemerly AS and Ferreira PC (2011). High efficiency and reliability of inter-simple sequence repeats (ISSR) markers for evaluation of genetic diversity in Brazilian cultivated Jatropha curcas L. accessions. Mol. Biol. Rep. 38: 4245-4256.

Jin Y, Zhang WJ, Fu DX and Lu BR (2003). Sampling stragegy within a wild soybean population based on its genetic 
variation detected by ISSR markers. Acta Bot. Sin. 45: 995-1002.

Khajudparn P, Prajongjai T, Poolsawat O and Tantasawat PA (2012). Application of ISSR markers for verification of F1 hybrids in mungbean (Vigna radiata). Genet. Mol. Res. 11: 3329-3338.

Lewontin RC (1972). The apportionment of human diversity. Evol. Biol. 6: 381-398.

Li KH, Zhou GX, Ren GL, Zhang XX, et al. (2011). Observation on ploidy levels of lily cultivars. Acta Hortic. Sin. 38: 970-976.

Lim KB, Gonzalez RB, Zhou SJ and Ramanna MS (2008). Interspecific Hybridization in Lily (Lilium): Taxonomic and Commercial Aspects of Using Species Hybrids in Breeding. Floriculture, Ornamental and Plant Biotechnology. Volume V, Global Science Books, London, 146-151.

Lin XC, Lou YF, Liu J, Peng JS, et al. (2010). Crossbreeding of Phyllostachys species (Poaceae) and identification of their hybrids using ISSR markers. Genet. Mol. Res. 9: 1398-1404.

Liu XM and Yang GC (2012). Adventitious shoot regeneration of oriental lily (Lilium orientalis) and genetic stability evaluation based on ISSR marker variation. In Vitro Cell. Dev. Biol. Plant 48: 172-179.

Miao HB, Chen FD, Zhao HB and Fang WM (2008). Genetic diversity and construction of fingerprinting of Chrysanthemum cultivars by ISSR markers. Sci. Agric. Sin. 41: 3735-3740.

Nei M (1973). Analysis of gene diversity in subdivided populations. Proc. Natl. Acad. Sci. U. S. A. 70: 3321-3323.

Peng LJ (2002). Lilies: Resources and Cultivation. Yunnan Nationalities Publishing house, Kunming, 1-4.

Qian W, Ge S and Hong DY (2001). Genetic variation within and among populations of a wild rice Oryza granulate from China detected by RAPD and ISSR markers. Theor. Appl. Genet. 102: 440-449.

Rao LS, Usha Rani P, Deshmukh PS and Kumar PA (2007). RAPD and ISSR fingerprinting in cultivated chickpea (Cicer arietinum L.) and its wild progenitor Cicer reticulatum Ladizinsky. Genet. Resour. Crop Evol. 54: 1235-1244.

Ruas PM, Ruas CF, Rampim L and Carvalho VP (2003). Genetic relationship in Coffea species and parentage determination of interspecific hybrids using ISSR (Inter-Simple Sequence Repeat) markers. Genet. Mol. Biol. 26: 319-327.

Sato T and Miyoshi K (2007). Restoration of intact anthers in a thermosensitive, antherless, malesterile cultivar of Asiatic hybrid lily in response to high temperature. J. Hortic. Sci. Biotech. 82: 791-797.

Senthil Kumar R, Parthiban KT and Govinda RM (2009). Molecular characterization of Jatropha genetic resources through inter-simple sequence repeat (ISSR) markers. Mol. Biol. Rep. 36: 1951-1956.

Taheri S, Abdullah TL, Abdullah NA and Ahmad Z (2012). Genetic relationships among five varieties of Curcuma alismatifolia (Zingiberaceae) based on ISSR markers. Genet. Mol. Res. 11: 3069-3076.

Tang L, Xiao Y, Li L, Guo Q, et al. (2010). Analysis of genetic diversity among Chinese Auricularia auricula cultivars using combined ISSR and SRAP markers. Curr. Microbiol. 61: 132-140.

Tian QS, Han B, Yang J, Yu T, et al. (2010). Genetic diversity analysis of 96 brome materials based on ISSR markers. J. Grassl. China 32: 18-25.

Wang HZ, Wu ZX, Lu JJ, Shi NN, et al. (2009a). Molecular diversity and relationships among Cymbidium goeringii cultivars based on inter-simple sequence repeat (ISSR) markers. Genetica 136: 391-399.

Wang J, Li H, Bao MZ and Liu GF (2009b). Production of interspecific hybrids between Lilium longiflorum and $L$. lophophorum var. linearifolium via ovule culture at early stage. Euphytica 167: 45-55.

Wang YQ, Fu Y, Yang Q, Deng QX, et al. (2010). Analysis of a germplasm collection of loquat using ISSR markers. Hort. Sci. 85: 113-118.

Wu XW, Cui GF, Wu LF, Zhang YP, et al. (2009). Identification of ISSR in Lily Hybrids. Acta Hortic. Sin. 36: 749-754.

Xi M, Sun L, Qiu S, Liu J, et al. (2012). In vitro mutagenesis and identification of mutants via ISSR in lily (Lilium longiflorum). Plant Cell Rep. 31: 1043-1051.

Yeh FC and Boyle TJB (1997). Population genetic analysis of co-dominant and dominant markers and quantitative traits. Belg. J. Bot. 129: 157.

Zeng L, Zhao LJ, Sun J, Zhao ZG, et al. (2010). Analysis of genetic relatedness of genetic resources of tagetes as revealed by ISSR. Sci. Agric. Sin. 43: 215-222.

Zhao J, Jiang P, Li N, Wang JF, et al. (2010). Analysis of genetic variation within and among Ulva pertusa (Ulvaceae, Chlorophyta) populations using ISSR markers. Chin. Sci. Bull. 55: 705-711.

Zhou SJ, Gonzalez RB, Lim KB and Ramanna MS (2008). Interspecific Hybridization in Lily (Lilium):Interploidy Crosses Involving Interspecific F1 Hybrids and Their Progenies. Floriculture, Ornamental and Plant Biotechnology. Volume V, Global Science Books, London, 152-156.

Zietkiewicz E, Rafalski A and Labuda D (1994). Genome fingerprinting by simple sequence repeat (SSR)-anchored polymerase chain reaction amplification. Genomics 20: 176-183.

Zuo ZR, Mu D, Gao JP and Liu C (2005). Studies on the genetic diversity and phylogenetic relationship of Lilium ssp. by RAPD technique. Acta Hortic. Sin. 32: 468-472. 